\title{
Preliminary Desorption Studies for HZ-PAN and AgZ-PAN
}

Nuclear Technology

Research and Development

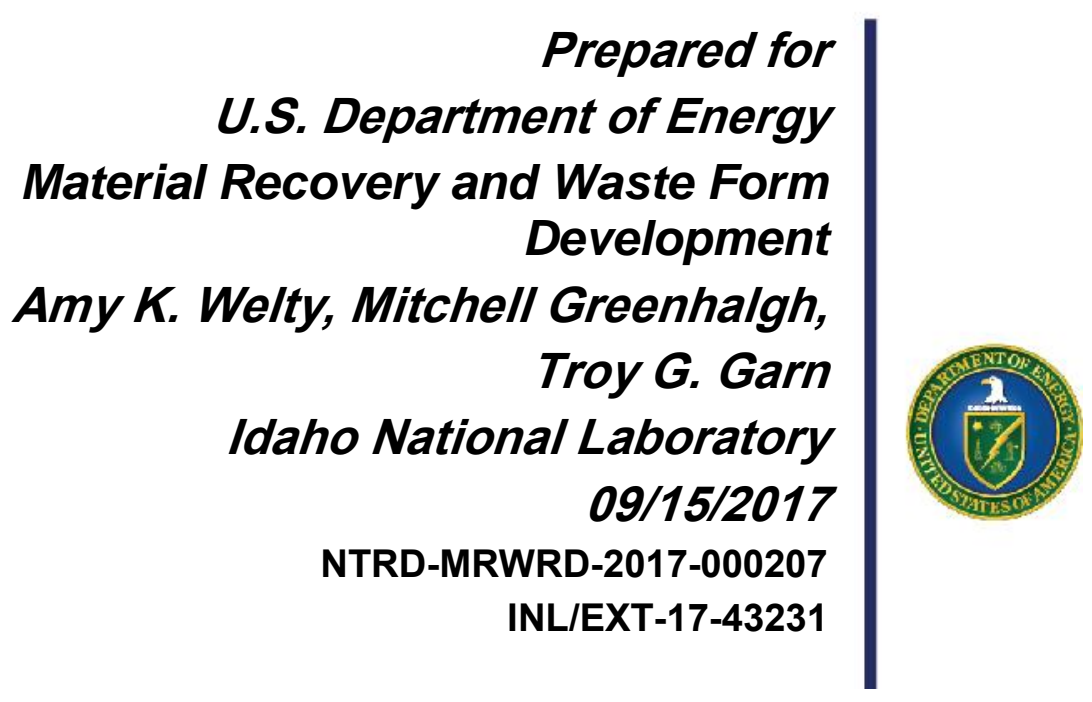





\section{DISCLAIMER}

This information was prepared as an account of work sponsored by an agency of the U.S. Government. Neither the U.S. Government nor any agency thereof, nor any of their employees, makes any warranty, expressed or implied, or assumes any legal liability or responsibility for the accuracy, completeness, or usefulness, of any information, apparatus, product, or process disclosed, or represents that its use would not infringe privately owned rights. References herein to any specific commercial product, process, or service by trade name, trade mark, manufacturer, or otherwise, does not necessarily constitute or imply its endorsement, recommendation, or favoring by the U.S. Government or any agency thereof. The views and opinions of authors expressed herein do not necessarily state or reflect those of the U.S. Government or any agency thereof. 



\section{SUMMARY}

Adsorption of $\mathrm{Kr}$ and $\mathrm{Xe}$ on HZ-PAN and AgZ-PAN has been studied extensively. Prior research focused on sorbent capacity and breakthrough of $\mathrm{Kr}$ and $\mathrm{Xe}$, with desorption cycles completed in order to close material balances and prepare sorbents for further adsorption testing. This series of tests was designed to determine preliminary information about desorption to guide further research in order to optimize product purification streams for desorption cycles for each sorbent.

A series of desorption tests were performed using thermal and pressure swing operations. For AgZ-PAN, test results indicated that both heat and sweep gas are likely necessary to remove adsorbed gases. Desorption data indicate the small amounts of $\mathrm{Kr}$ adsorbed on AgZ-PAN can be separated from the bulk Xe using temperature control. A combination of vacuum and heat may be sufficient to desorb gases from HZ-PAN, which should result in a purer $\mathrm{Kr}$ stream during desorption. Further, initial testing indicates separation of $\mathrm{Kr}$ from Xe during vacuum desorption. Desorption processes for both sorbents merits further study in order to more fully characterize desorption streams from each sorbent, understand and control separation of $\mathrm{Kr}$ and $\mathrm{Xe}$ from each other and from the bulk gas stream, and optimize desorption to minimize final waste form volumes. 


\section{CONTENTS}

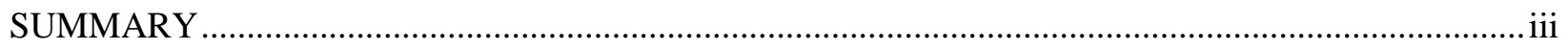

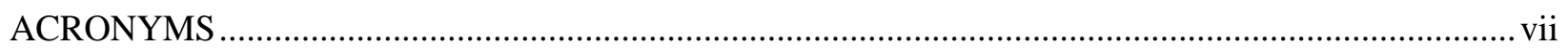

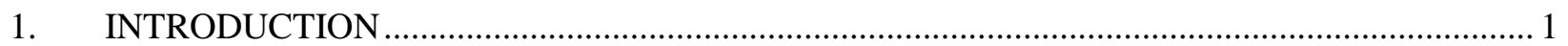

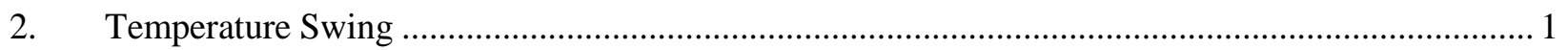

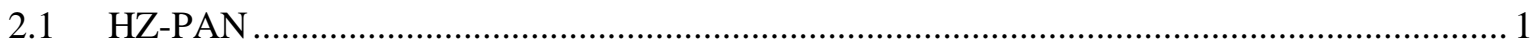

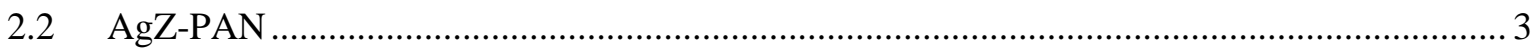

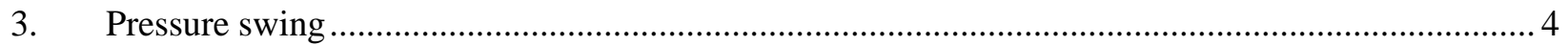

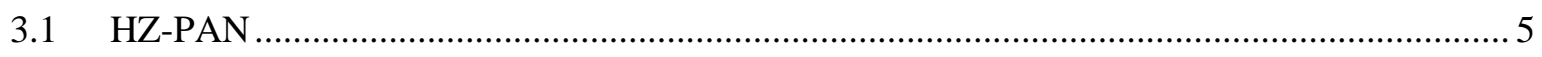

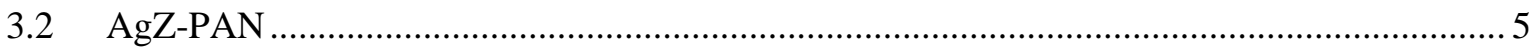

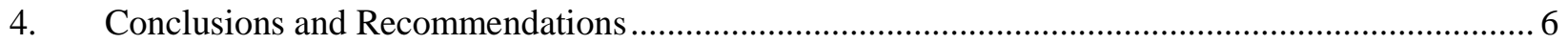

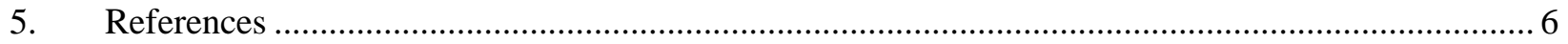

\section{FIGURES}

Figure 1. Desorption from AgZ-PAN with rapid heating ............................................................... 3

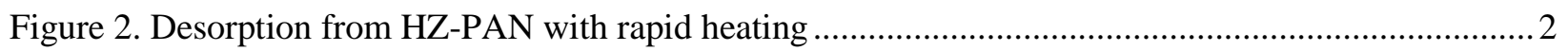

Figure 3. Desorption from HZ-PAN while slowly heating from $191 \mathrm{~K}$ to $420 \mathrm{~K}$ over 12 hours ..................2

Figure 4. Desorption from AgZ-PAN while slowly heating from $253 \mathrm{~K}$ to $420 \mathrm{~K}$ over 12 hours ................ 3

Figure 5. Desorption from AgZ-PAN while slowly heating form $295 \mathrm{~K}$ to $420 \mathrm{~K}$ over 12 hours. ............... 4

\section{TABLES}

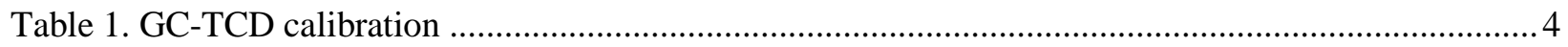

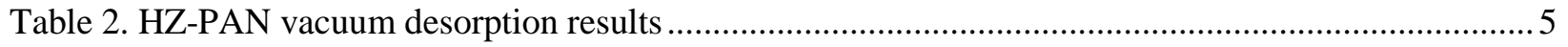

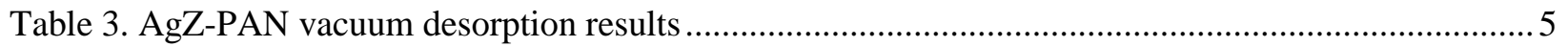




\section{ACRONYMS}

AgZ-PAN Engineered form silver mordenite in polyacrylonitrile matrix

HZ-PAN Engineered form hydrogen mordenite in polyacrylonitrile matrix

INL Idaho National Laboratory

$\mathrm{Kr} \quad$ Krypton

Xe Xenon 


\section{PRELIMINARY DESORPTION STUDES FOR HZ-PAN AND AGZ-PAN}

\section{INTRODUCTION}

Reprocessing of used nuclear fuel emits several volatile radionuclides. In order to meet US regulatory emission requirements, they will need to be removed from the bulk gas stream prior to release. INL has developed and tested sorbents, AgZ-PAN and HZ-PAN, to remove Xe and $\mathrm{Kr}$ from the bulk gas stream. To date, this research has primarily focused on the adsorption properties of the sorbents. Recent engineering studies (Jubin, et al., 2016) (Jubin, et al., 2017) indicated a need for desorption data in order to advance the technology readiness for development of integrated off-gas treatment systems.

\section{Temperature Swing Desorption Testing}

The majority of the research to date has used thermal swing operations for adsorption and desorption, successfully achieving complete desorption of $\mathrm{Xe}, \mathrm{Kr}$ and air from the sorbents. Feed gas consisting of $1000 \mathrm{ppm} \mathrm{Xe}$ and $150 \mathrm{ppm} \mathrm{Kr}$ in was used for adsorption, with AgZ-PAN operating at 295K or 253K, while HZ-PAN temperature was $191 \mathrm{~K}$. During those tests, desorption was accomplished by rapidly raising column temperature to $420 \mathrm{~K}$ with He flow and maintaining that temperature until no further $\mathrm{Kr}$, $\mathrm{Xe}$ and air were detected in the column effluent. While that method succeeded in desorbing all captured species from the AgZ-PAN and HZ-PAN sorbents, it ineffectively separated targeted adsorbed species from the bulk stream.

Desorption with rapid heating resulted in a mixed gas stream. However, the effluent concentration profiles of the $\mathrm{Kr}$ and $\mathrm{Xe}$ as temperature increased provided some indication that further separation is better achieved with carefully controlled temperature increases. In order to determine if thermal separation of gas species was possible, a very slow temperature gradient was used, along with He flow. A programmable controller was used to control the column temperature rate from adsorption temperatures to $420 \mathrm{~K}$ over the course of 12 hours. While the long time frame is likely undesirable for plant operations, it was chosen to determine optimum desorption temperatures for the sorbents. Future research will seek to exploit those temperatures. All tests were run in a multi-column configuration for adsorption. AgZcolumns were operated to Xe capacity, and Xe was intentionally allowed to break through the AgZ-PAN, resulting in small amounts of Xe adsorbed on the HZ-PAN columns to determine if separation during desorption was possible.

\subsection{HZ-PAN}

Previous testing of HZ-PAN, with rapid heating during desorption, resulted in very little separation of $\mathrm{Kr}$ from Xe in the effluent stream (Figure 1). 


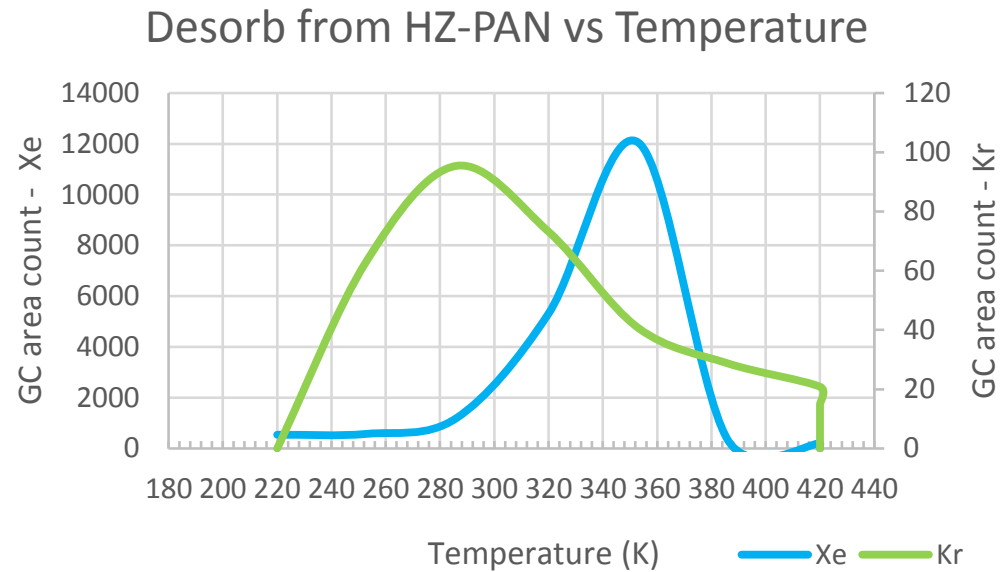

Figure 1. Desorption from HZ-PAN with rapid heating

Slowly raising column temperature during desorption, however, resulted in very nearly complete separation of $\mathrm{Kr}$ from Xe during desorption (Figure 2). The majority of the $\mathrm{Kr}$ was removed from the sorbent at $240 \mathrm{~K}$ and was entirely desorbed by the time column temperature reached $250 \mathrm{~K}$, at which point Xe started to desorb.

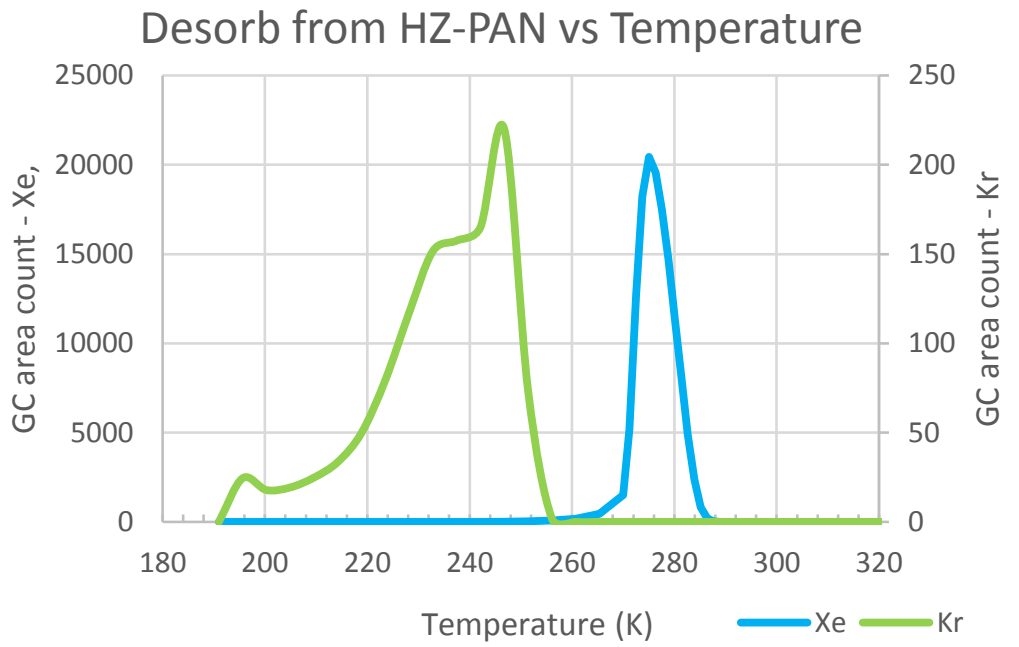

Figure 2. Desorption from HZ-PAN while slowly heating from 191K to 420K over 12 hours

Separation efficiency was not quantified as this research was intended to determine whether or not separation is possible during desorption. Further testing will be required to quantify separation efficiency and optimize desorption.

Although ideally operating Xe adsorption columns would be controlled to avoid Xe breakthrough to the $\mathrm{Kr}$ adsorption columns, there is a possibility for Xe bleed due to upset conditions or a minute amount of bleed through so small that it can't be measured. In order to minimize Kr storage volume, separating even those small quantities of $\mathrm{Xe}$ from the $\mathrm{Kr}$ will be important. 


\subsection{AgZ-PAN}

AgZ-Pan columns were operated long enough to ensure Xe breakthrough and continued to nearly full Xe capacity. As in previous testing, the AgZ-PAN also adsorbed a very small amount of Kr. Rapid heating of AgZ-PAN resulted in no separation of adsorbed $\mathrm{Kr}$ from Xe (Figure 3).

\section{Desorb from AgZ-PAN vs Temperature}

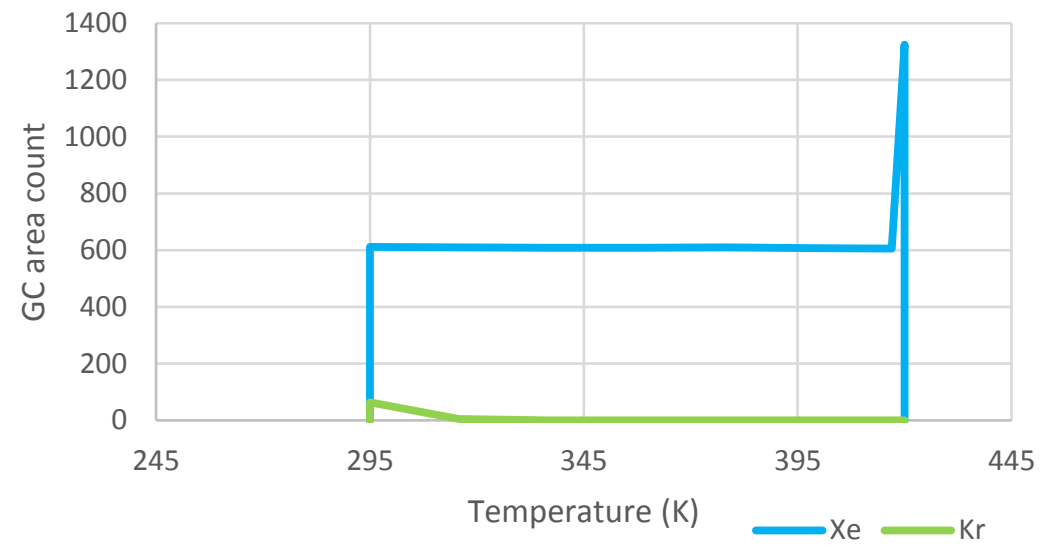

Figure 3. Desorption from AgZ-PAN with rapid heating

Slow heating, however, revealed a sizeable temperature gap between $\mathrm{Kr}$ and $\mathrm{Xe}$ desorption. The gap is not as pronounced when starting from an adsorption temperature of $295 \mathrm{~K}$ (Figure 5) as it is at an adsorption temperature of $253 \mathrm{~K}$ (Figure 4). Nevertheless, there is still a sizeable gap that should be exploitable to achieve further separation.

\section{Desorb from AgZ-PAN vs Temperature}

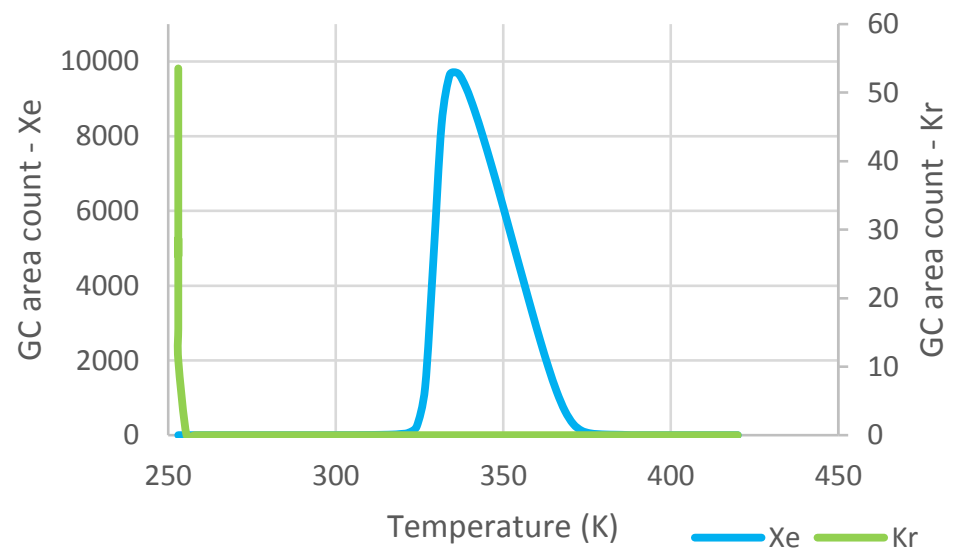

Figure 4. Desorption from AgZ-PAN while slowly heating from $253 \mathrm{~K}$ to $420 \mathrm{~K}$ over 12 hours 


\section{Desorb from AgZ-PAN vs Temperature}

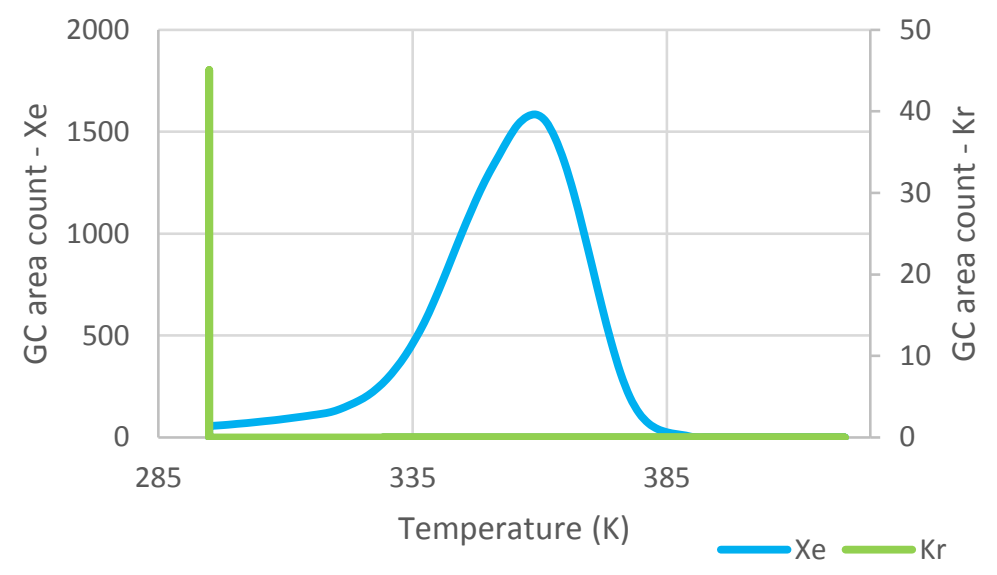

Figure 5. Desorption from AgZ-PAN while slowly heating from 295K to 420K over 12 hours.

As for HZ-PAN, desorption separation efficiency was not quantified for AgZ-PAN. Further research is necessary to optimize desorption for the most efficient separation of $\mathrm{Kr}$ from $\mathrm{Xe}$ and from the bulk air stream.

\section{Pressure Swing Desorption Testing}

Initial adsorption of gas species on the columns was accomplished in the same manner as for the temperature tests, intentionally running the AgZ-PAN to nearly full capacity and allowing Xe to break through to the HZ-PAN. No Xe was measured in the effluent from the HZ-PAN. Desorption was accomplished by using a GAST ROA series rocking piston vacuum pump/air compressor to pull a vacuum on the columns and force desorbed gases into $6 \mathrm{~L}$ sample bombs. As these tests were preliminary in nature, gases were removed in bulk from the columns at the maximum achievable vacuum, $-25 \mathrm{in} . \mathrm{Hg}$, with no attempt to determine gas concentrations over a vacuum gradient. GC-TCD was used for gas analysis.

The GC-TCD used for gas analysis was the same one used for adsorption testing, using an auto-sampling valve through a 1-mL sample loop. Desorption samples were taken from the sample bombs with a 1-mL gas sampling syringe and injected into the GC for analysis. Prior to desorption sample analysis, calibration of the GC was done with this sampling method. Testing feed gas of $1000 \mathrm{ppm} \mathrm{Xe}$ and 150 ppm $\mathrm{Kr}$ in air was used for calibration (Table 1).

Table 1. GC-TCD calibration

\begin{tabular}{c|ccc|cc} 
& \multicolumn{3}{|c|}{ GC area } & & $\begin{array}{c}\text { Standard } \\
\text { Deviation }\end{array}$ \\
Sample & 1 & 2 & 3 & Average & 0.294 \\
\hline \hline $\mathbf{K r}$ & 80.9 & 81.1 & 80.4 & 80.8 & 2.15 \\
$\mathbf{X e}$ & 743.9 & 744.7 & 739.8 & 742.8 & \\
\hline
\end{tabular}




\subsection{HZ-PAN}

After adsorption, column temperature was held at 191K. The sample bomb, with initial pressure of -22 in. $\mathrm{Hg}$, was attached and sample valves were opened. Sample bomb pressure immediately rose to $-18 \mathrm{in} . \mathrm{Hg}$ and remained there with the vacuum pump/compressor operating. The cooler was turned off and column temperature was allowed to rise to $293 \mathrm{~K}$, at which point sample bomb pressure was $-6 \mathrm{in}$. $\mathrm{Hg}$. Heat was applied to the column to raise temperature to $373 \mathrm{~K}$, resulting in a sample bomb pressure of 4 psi, at which point sample valves were closed.

Sample analysis was run in triplicate, with results indicating Kr only, with no Xe detected (Table 2).

Table 2. HZ-PAN vacuum desorption results

\begin{tabular}{c|ccc|cc} 
Sample & 1 & 2 & 3 & Average & $\begin{array}{c}\text { Standard } \\
\text { Deviation }\end{array}$ \\
\hline \hline $\mathbf{K r}(\mathbf{p p m})$ & 339.1 & 347.2 & 344.9 & 343.8 & 3.41 \\
$\mathbf{X e}(\mathbf{p p m})$ & 0 & 0 & 0 & 0 & 0.00 \\
\hline
\end{tabular}

Of the gases adsorbed on the HZ-PAN, $66 \%$ of the $\mathrm{Kr}$ and none of the Xe was removed with vacuum. He sweep gas was used to complete desorption. GC-TCD analysis of the desorbed gas with He sweep determined that there was Xe adsorbed on the HZ-PAN, as expected. Xe remaining on the HZ-PAN under vacuum indicates additional separation during vacuum desorption. Further research is necessary to quantify separation for desorption optimization.

\subsection{AgZ-PAN}

After adsorption, column temperature was held at $295 \mathrm{~K}$. The sample bomb, with initial pressure of $-22 \mathrm{in}$. $\mathrm{Hg}$ was attached and sample valves were opened. With the vacuum pump/compressor operating, pressure rose to $-20 \mathrm{in}$. $\mathrm{Hg}$. After column temperature was raised to $420 \mathrm{~K}$, sample pressure reached $10 \mathrm{psi}$, at which point sample valves were closed.

Samples analysis was run in triplicate, with no $\mathrm{Kr}$ detected (Table 3)

Table 3. AgZ-PAN vacuum desorption results

\begin{tabular}{c|ccc|cc} 
Sample & 1 & 2 & 3 & Average & $\begin{array}{c}\text { Standard } \\
\text { Deviation }\end{array}$ \\
\hline \hline $\mathbf{K r}(\mathbf{p p m})$ & 0.0 & 0.0 & 0.0 & 0.0 & 0.00 \\
$\mathbf{X e}(\mathbf{p p m})$ & 381.3 & 379.0 & 381.5 & 380.6 & 1.15 \\
\hline
\end{tabular}

Only $12 \%$ of the total adsorbed Xe was removed with vacuum. He sweep gas was required for complete desorption. 


\section{Conclusions and Recommendations}

These tests were intended to be preliminary in nature, providing sufficient data to direct further research for desorption optimization of AgZ-PAN and HZ-PAN. Results indicate that further separation of $\mathrm{Kr}$ and $\mathrm{Xe}$ from the bulk gas stream should be possible with careful control of pressure and/or temperature during desorption. For HZ-PAN, the bulk of the $\mathrm{Kr}$ was removed with vacuum, minimizing sweep gas volume necessary for desorption. This is of particular interest as it may help to minimize volume of the final $\mathrm{Kr}$ waste form.

Both temperature and pressure swing desorption results indicate gaps between desorption of species of interest. Although the effluent streams from desorption have not yet been fully characterized, there is sufficient information from GC-TCD analysis to suggest that air is adsorbed to some extent on both sorbents. Further research is necessary to determine the concentration of air and other undesirable species on the sorbent and if the gaps identified during this research may be exploited to achieve further separation of $\mathrm{Kr}$ and $\mathrm{Xe}$ from each other and the bulk gas stream.

\section{References}

Jubin, R. T., Bruffey, S. H., Jordan, J. A., Spencer, B. B., Soelberg, N. R., Welty, A. K., \& Greenhalgh, M. R. (2017). Data Requirements and Test System Needs for Development of an Integrated OffGas Treatment System. ORNL.

Jubin, R. T., Jordan, J. A., Spencer, B. B., Soelberg, N. R., Welty, A. K., Greenhalgh, M., .. . Thallapally, P. K. (2016). Engineering Evaluation of an Integrated Off-Gas Treatment System for Used Nuclear Fuel Reprocessing Facilities. ORNL. FCRD-MRWFD-2016-000313. 